\title{
Anti-tumor Effects of Scorpion Peptide Smp43 Through Mitochondrial Dysfunction and Membrane Disruption on Hepatocellular Carcinoma
}

Jinwei Chai ${ }^{\dagger}$, Wanren Yang ${ }^{\ddagger}$, Yahua Gao ${ }^{\dagger}$, Ruiyin $\mathrm{Guo}^{\dagger}$, Qing Peng ${ }^{\ddagger}$, Mohamed A.

Abdel-Rahman $^{\S}$, Xueqing $\mathrm{Xu}^{\dagger} *$

${ }^{\dagger}$ Guangdong Provincial Key Laboratory of New Drug Screening, School of Pharmaceutical

Sciences, Southern Medical University, Guangzhou 510515, China; ${ }^{\ddagger}$ General Surgery Center, Department of Hepatobiliary Surgery II, Guangdong Provincial Research Center for Artificial Organ and Tissue Engineering, Zhujiang Hospital, Southern Medical University, Guangzhou

510280, China; ${ }^{\S}$ Zoology Department, Faculty of Science, Suez Canal University, Ismailia 41522, Egypt.

\section{Contents:}

Supplementary Methods

Supplementary Tables 1

Supplementary Figures 1 - 3 


\section{Supplementary Methods}

Peptide synthesis and purification. Smp43 was synthesized by GL Biochem Ltd. (Shanghai, China). Subsequently, an Inertsil ODS-SP (C18) reverse-phase HPLC column (SHIMAZU, Ōsumi, Japan) was used to purify the crude synthetic peptide with a linear gradient of water and acetonitrile (both containing $0.1 \% \mathrm{TFA}$ ) at a flow rate of $1 \mathrm{ml} / \mathrm{min}$. Once the purity computed on the basis of the ratio of different peak areas was higher than $95 \%$, the peak was pooled, lyophilized, and further verified by MALDI-TOF mass spectrometry (Figure S1). FITC-labelled Smp43 was obtained with FITC conjugation kit (Sangon; Shanghai; China).

Toxicity analysis. To detect the acute toxicity of Smp43 in vivo, the mice were weighed and randomly divided into three groups with 3 animals each, and Smp43 $(5 \mathrm{mg} / \mathrm{kg}$ and $10 \mathrm{mg} / \mathrm{kg}$ ) and saline were intraperitoneally administered into mice of different groups. At $48 \mathrm{~h}$ after injection, serum and organ tissues from mice were collected for blood biochemical detection and organ/body weight ratio analysis, respectively. 


\section{Supplementary Tables}

\begin{tabular}{cll}
\hline Patient characteristics & ID:2990221 & ID: 3279703 \\
\hline Age (years)/sex & $53 /$ male & $61 /$ male \\
HBsAg & $3475 \mathrm{COI} \quad$ (positive) & $0.321 \mathrm{COI}$ (negative) \\
Serum HBV DNA & $3.07 \times 10^{\wedge} 4 \mathrm{IU} / \mathrm{mL}$ & not dected \\
Anti-HCV antibody & $0.035 \mathrm{COI} \quad($ negative) & $0.044 \mathrm{COI}$ (negative) \\
Serum $\boldsymbol{\alpha}$-fetoprotein & $28.5 \mu \mathrm{g} / \mathrm{L}$ & $2.2 \mu \mathrm{g} / \mathrm{L}$ \\
HCC pathologic & moderated differentiated HCC; & moderated differentiated HCC; \\
$\quad$ diagnosis & Vascular invasion;No cirrhosis & Vascular invasion;No cirrhosis \\
\hline
\end{tabular}




\section{Supplementary Figures}


Figure S1. The synthesis and characterization of Smp43. (A) RP-HPLC. (B) MALDI-TOF-MS. 

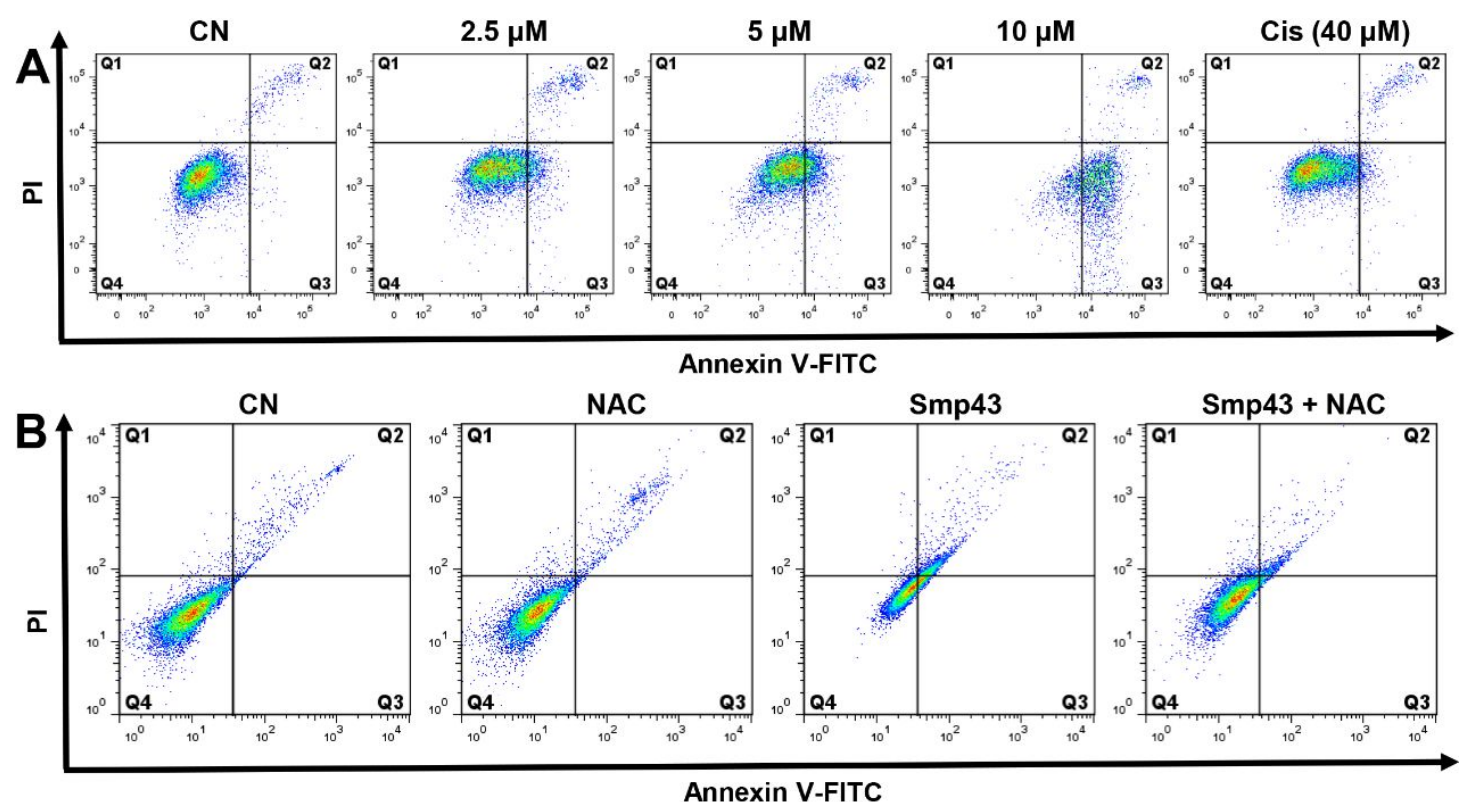

Figure S2. Determination of the mode of cell death using Annexin-V FITC and PI staining and flow cytometric analysis. A. Cells were exposed to $2.5,5$ and $10 \mu \mathrm{M}$ of Smp 43 or $40 \mu \mathrm{M}$ Cis, then stained with Annexin V-FITC/PI and analyzed on flow cytometry. B. $5 \mu \mathrm{M}$ Smp43 plus NAC ( $2 \mathrm{mM})$ which was added into cells at $1 \mathrm{~h}$ prior to addition of Smp43 before stained by the Annexin V-FITC/PI staining kit. 


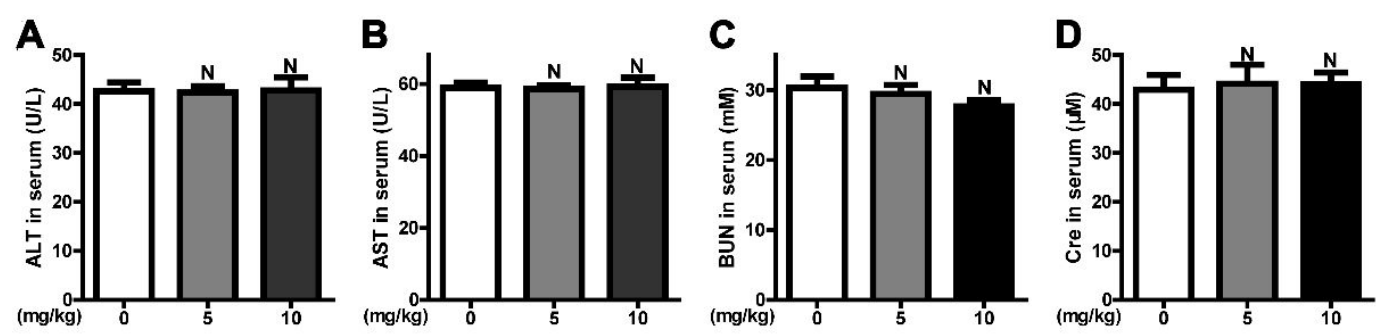

Figure S3. Toxicity analysis of Smp43. The level of ALT (A), AST (B), BUN (C), Cre (D) in serum of normal mice were detected after $48 \mathrm{~h}$ treatment with 0,5 and $10 \mathrm{mg} / \mathrm{kg}$ Smp43., respectively. 